\title{
Effects of Neuromuscular Electrical Stimulation on Hemiplegic Upper Limb of Stroke Survivors: A Meta- Analysis of Randomized Controlled Trials
}

\section{Wenyue Zhang}

Chongqing Medical University Second Affiliated Hospital

\section{Shuye Pei}

Affiliated Hospital of Inner Mongolia Medical College

\section{Juan Huang}

Chongqing Medical University Second Affiliated Hospital

\section{Yao Tang}

Chongqing Medical University Second Affiliated Hospital

Huaidong Hu ( $\nabla$ huhuaidong@cqmu.edu.cn )

Chongqing Medical University Second Affiliated Hospital

\section{Research article}

Keywords: Neuromuscular electrical stimulation, stroke, hemiplegia, upper limb, Meta-analysis

Posted Date: December 23rd, 2019

DOI: https://doi.org/10.21203/rs.2.19509/v1

License: (c) (i) This work is licensed under a Creative Commons Attribution 4.0 International License. Read Full License 


\section{Abstract}

Background: Whether NMES helps the recovery of upper limb function in patients with hemiparesis has not been confirmed. We conducted this meta-analysis to examine the effectiveness of neuromuscular electrical stimulation (NMES) for upper limb hemiparesis after stroke.

Methods: Data sources such as Pubmed, Embase and Cochrane library databases were searched for all relevant studies that were carried out before December 1, 2018.We selected the randomized controlled trials (RCTs) which included chronic and acute stroke patients with upper extremity dysfunction. Then the intervention group which applied NMES was compared with a control group without NMES.

Results: A total of 16 RCTs involving 691 patients were discerned from 248 searched articles. According to the forest plot ,NMES had a significant benefit on FMA-ue scale(SMD=0.44,95\% CI 0.13 to $0.74, P=0.006)$. Also, NMES was positive for ARAT(SMD=0.31,95\% Cl 0.05 to $0.58, \mathrm{P}=0.019$ ) and $\mathrm{MAL}-\mathrm{AOU}(\mathrm{SMD}=0.59,95 \% \mathrm{Cl} 0.15$ to1.04, $\mathrm{P}=0.009)$, but not for wrist $\mathrm{MAS}(\mathrm{SMD}=-0.12,95 \% \mathrm{Cl}-0.43$ to $0.19, \mathrm{P}=0.434)$ or $\mathrm{BI}(\mathrm{SMD}=0.51,95 \% \mathrm{Cl}-0.65$ to $1.66, P=0.392)$.

Conclusion: NMES application has beneficial impacts on upper extremity motor function in patients with stroke. This study suggests that NMES ought to be applied as a beneficial rehabilitation means in improving the upper function.

\section{Background}

Stroke accounts for at least $5 \%$ of all disability-adjusted life years (DALYs), and $10 \%$ of all deaths worldwide ${ }^{1,2}$. Overall, the total global burden of stroke is increasing, and the majority of this burden (over $75 \%$ stroke deaths and $81 \%$ of DALYs) comes from low- and middle-income countries ${ }^{3}$. Importantly, over two-thirds of stroke deaths worldwide are in developing countries ${ }^{4}$. The most common complication among hemiplegic patients after stroke is the limitation in activity of the upper limb, and recovery is often observed to be poor ${ }^{5}$. Muscle paresis/weakness and hypertonia/spasticity can be impediments to motor function and cause pain ${ }^{6}$. The most frequently received complaint during upper limb physical treatment is the pain associated with passive exercise ${ }^{5}$.Under this condition, the application of NMES can stimulate muscles, change muscle paresis/weakness or hypertonia/spasticity to relieve pain from passive exercise. In addition, due to somatosensory changes, muscle fiber contents, the motor unit recruitment ability is reduced, also reducing its exercise capacity ${ }^{7}$. To facilitate recovery from this condition, NMES does not only alleviate disability through promoting the recovery of volitional movement (therapeutic effect), but also replace lost volitional movement (neuroprosthetic effect) ${ }^{8}$. Additionally, NMES therapy can also be used for strength training in disuse muscle atrophy caused due to long-term inactivity, surgery or injury, thereby maintaining muscle mass, improving joint mobility, promoting voluntary muscle control, and reducing paralysis ${ }^{9}$. NMES therapy is not the simply electrical stimulation, it also involved functional electrical stimulation (FES), therapeutic electrical stimulation (TES) , electromyogram (EMG) triggered NMES and so on ${ }^{10}$. NMES contains the use of a battery-operated, small self-adhesive electrode, producing controllable stimulation, which drives the muscle contraction capacity from $20 \%$ to $40 \% 11,12$. This analysis was designed to examine the effectiveness of the NMES intervention in improving upper extremity motor function in hemiparesis patients after stroke when compared to a control group. 


\section{Methods}

\section{Literature search}

At the time of initial online retrieval, two independent investigators (ZWY and PSY) assessed the titles and abstracts of the articles and relevant references and then screened out the necessary data from accessible full-text articles. An online article search included two aspects: (i) Clinical studies published in the following electronic databases: PubMed, Embase, and Cochrane Library, (ii) several Chinese articles which found in the references ${ }^{13-15}$. All the studies included in this work were published before December 2018 without any language restrictions. The MeSH terms that were searched for were as follows: (Hemiplegias OR Hemiplegia, Transient OR Transient Hemiplegias) AND (Electrical Stimulation OR Electrical Stimulations OR Stimulation, Electric OR Stimulations, Electrical) AND (Upper Limb OR Upper Extremities OR Membrum superius OR Limbs, Upper) AND (Randomized OR Randomized controlled trial). In addition, various synonyms were also searched for.

Inclusion and exclusion criteria:

The purpose of this study was to explore the role of NMES in the recovery of upper limb function in stroke patient. Subjects of both sexes, aged more than 18 years, Inclusion criteria for selecting the articles included: (1) the design of selected trials were randomized controlled trials $₫ R C T s \otimes$ and participants were human, (2) the participants were clinically diagnosed as having acute or chronic hemiplegia after stroke with stable vital signs, (3) all experimental groups applied NMES such as FES, EMG-triggered NMES and, (4) at least one contrast group was included,(5) the study aim of the included trials were patients' upper limbs,(6) the parameters in the trials included at least the FMAue, ARAT, MAL-AOU or wrist MAS, and (7) the data of selected trials must included mean \pm SD (or $95 \% \mathrm{Cl}$ ) in order to conduct forest plot analysis. Additionally, the exclusion criteria were set as follows: (1) stroke survivors without hemiparesis, (2) age < 18 years or pregnant, (3) lacking a contrast group and insufficient data even after contacting the author twice by e-mail, (4) intervention duration of <2 weeks, (5)the main measurement scales were not include FMA-ue or ARAT, and (6) the included trials focused only on lower limb studies.

Data extraction:

Type of study design, characteristics of participants, number of patients, duration of intervention, main outcome measures, year of publication, gender, and type of interventions were extracted and showed in the Table1. Also included were the mean \pm SD (or $95 \% \mathrm{Cl}$ ) of all previously specified measures. Only data of the intervention period between 2 weeks and 24 weeks were extracted to control the relative heterogeneity. Emails were sent to the authors in order to obtain complete data in case they were incomplete.

Study quality assessment:

ZWY and PSY assessed the risk of bias according to the Cochrane Handbook for Systematic Reviews of Interventions ${ }^{16}$. As per this guide; the study quality assessment was divided into six aspects: random sequence generation, allocation concealment, blinding, incomplete outcome data, selective reporting, and other bias. Each aspect of the risk of bias involved 3 evaluation results: low, unclear, or high. The outcomes of assessment were illustrated in the Results section. In addition, Funnel plots, Egger's test and Begg's test were applied to assess the publication bias of literature.

Statistical analysis: 
We applied the Stata version 12.0 (Stata Corporation, College Station, TX, USA) to analyze these trials. Only continuous variables were available and were extracted in this analysis. Among all, 16 RCTs data were all Mean \pm SD and two were $95 \% \mathrm{Cl}^{17,18}$. The Chi-squared and I-square $\left(\mathrm{I}^{2}\right)$ tests were used to analyse trial statistical heterogeneity. The random-effects model was used to study the obvious heterogeneity $\left(P<0.1 \text { and I }{ }^{2}>50 \%\right)^{19}$; in other cases, a fixed-effect model was conducted. We assumed the heterogeneity exist among selected trials and applied random-effects model to verify it. If not, fixed-effect model was conducted. When P-value $<0.05$, it implied that the statistical significance existed between the intervention and control group. In addition, when the SMD value was closing to 0 ( $P>0.05)$, it showed that no statistical significance existed. And a "significant finding" means that the SMD value was far from $0(P<0.05)$. Subgroup analyses were conducted based on the duration of intervention ( $\leq 4$ weeks and $₫ 4$ weeks) and area (North America, Europe, and Asia).

\section{Results}

Summary of included studies

On initial online search and relevant references, 248 articles were included. Filter by title, abstract, repetition, and content, most of the unqualified articles have been filtered out. Careful assessment of 21 full-text articles led to the exclusion of 2 studies $^{20,21}$ because of lacking a control group, another 3 studies ${ }^{22-24}$ were excluded due to incomplete data. Therefore, a total of 16 randomized controlled trials (RCTs) with 691 acute or chronic individuals fulfilled the inclusion criteria and were applied to this meta-analysis. The detailed screening process was showed in the form of PRISMA diagram ${ }^{25}$ in Fig 1.

The summary of the basic characteristics of the included studies is presented in Table 1 . The 5 studies $^{13-15,17,26}$ were performed in China, and 2 were conducted in Japan ${ }^{27,28}$ and 3 were conducted in America ${ }^{18,29,30}$. The rest of the studies were carried out in Switzerland ${ }^{31}$, Turkey ${ }^{32}$, Spain $^{33}$, Canada ${ }^{34}$, England ${ }^{35}$ and Netherlands ${ }^{36}$, respectively. The shortest duration of intervention among these trials was of 2 weeks. In addition, the types of electro-stimulation used were FES, EMG-triggered NMES and NMES with the forms in which, NMES electrode sheets were stuck to the skin surface or a robot arm was driven by NMES. And the allocation of the electrode sheets were generally attached on the muscles of extensor/ flexor carpi radialis, extensor digitorum communis, anterior/posterior deltoid and triceps muscles.

\section{Data quality:}

The assessment regarding the risk of bias among each trial is shown in Supplementary file S1. Amongst all, these selected trials were different in study quality: besides $12^{17,18,26,28-36}$ blind trials were at low risk of bias, one study ${ }^{27}$ was assessed as high risk of bias out of not blind. $2^{35,36}$ trials adopted concealed allocation, which were regarded as low risk of bias. Also, all of the involved trials were at an unclear risk of bias in selective reporting. One study $^{34}$ was at high risk of bias due to incomplete outcome data. Moreover, 6 studies ${ }^{17,18,28,31,33,35}$ were at low risk of bias due to random sequence generation by computer or pseudorandom number sequence. One study ${ }^{36}$ was at high risk of bias for free of other sources of bias.

Meta-analysis:

Pooled data from $13^{13-15,17,18,26,27,29-32,34,36}$ trials ( $\mathrm{n}=645$ for all experiments and controls) showed obvious efficacy on performing the FMA-ue assessment $(S M D=0.44,95 \% \mathrm{Cl} 0.13$ to $0.74, \mathrm{P}=0.006)$. Additionally, NMES 
treatment did not display a positive effect on the wrist MAS $\triangle S M D=-0.12,95 \% \mathrm{Cl}-0.43$ to $0.19, \mathrm{P}=0.434$ ). The metaanalysis of $517,26,33,35,36$ studies implied a distinct benefit in the intervention group $(n=114)$ in improving ARAT, which had inconspicuous heterogeneity compared with the control group ( $n=113)$ (SMD $=0.31,95 \% \mathrm{Cl} 0.05$ to $\left.0.58, \mathrm{P}=0.019, \mathrm{I}^{2}=0 \%\right)$. Moreover, NMES therapy was effective when measured by MAL-AOU score $(\mathrm{SMD}=0.59,95 \% \mathrm{Cl} 0.15$ to $1.04, \mathrm{P}=0.009)$, which contrasts with $\mathrm{BI}$ score $(\mathrm{SMD}=0.51,95 \% \mathrm{Cl}-0.65$ to $1.66, \mathrm{P}=0.392)$ that exhibited no benefit in upper limb rehabilitation (Fig 2A-E).

Subgroup analyses:

Subgroups were divided into 2 aspects: (i) duration of intervention and (ii) area. Outcomes of the subgroup analyses are concluded in Supplementary file S2. When grouped by duration, a significant improvement within the duration of $\leq 4$ weeks were observed in the FMA-ue (SMD $=0.43,95 \% \mathrm{Cl} 0.05$ to $0.81, \mathrm{P}=0.027), \mathrm{ARAT}(\mathrm{SMD}=0.42$, $95 \% \mathrm{Cl} 0.04$ to $0.79, \mathrm{P}=0.03)$ and $\mathrm{MAL}-\mathrm{AOU}(\mathrm{SMD}=0.55,95 \% \mathrm{Cl} 0.07$ to $1.02, \mathrm{P}=0.025)$,but not in the duration of longer than 4 weeks. The subgroup analyses conducted to differentiate the area to which the participants belonged to showed a significant improvement in the FMA-ue (SMD $=0.57,95 \% \mathrm{Cl} 0.14$ to $1.01, \mathrm{P}=0.009)$ and ARAT (SMD $=0.42$, $95 \% \mathrm{Cl} 0.04$ to $0.79, \mathrm{P}=0.03$ ) scores among Asians. And the MAL-AOU score was positive in people from North America (SMD=1.43, 95\% Cl 0.41 to $2.45, \mathrm{P}=0.006)$.

Publication bias of literature

To evaluate the publication bias, Funnel plots, Egger's test and Begg's test were conducted successively, except the condition that selected trials were less than 10 in each meta-analysis. In this meta-analysis, only the FMA-ue scale met the above standard ,which involved total 16 trials. So the Begg 's and Egger's approaches can be assessed $(P=0.224)$ ( in Fig 3), and was deemed to show no publication bias.

\section{Discussion}

Although one published review reported the improvement efficiency of EMG-NMES in body structure and function domain of the international classification of functionality, disability, and health (ICF), it failed to analyze the specific parameters within scales and define the duration of intervention among subgroup analyses in vague ${ }^{37}$. According to this meta-analysis, we concluded that NMES can improve upper limb function with changing of the FMA-ue, ARAT and MAL-AOU scores among patients suffered from hemiparesis.Also, the subgroup analyses suggested that less duration of intervention ( $\leq 4$ weeks) is more effective than longer duration ( $₫ 4$ weeks) in the improvement of FMA-ue, ARAT and MAL-AOU. And people from Asia showed significant improvement in FMA-ue and ARAT. The limited data on North Americans and Europeans makes it challenging to draw any conclusions with this area.

The best recovery period is around the first 10 weeks after the occurrence of stroke, with chances of spontaneous neurological recovery 38,39 , and $4 \%$ to $27 \%$ poststroke spasticity usually occurs during1-4 week's post-stroke, so we selected 4 weeks as a boundary ${ }^{40}$. In addition, the experiments by Fang et al (2004) ${ }^{13}$ and Li et al (2009) ${ }^{15}$ considered the duration of the rehabilitation as an intervention period, so the typical intervention period was not mentioned but definitely more than 4 weeks. In this analysis, SMD was used to measure the experimental data instead of WMD due to the mean difference was too large and exceeded 10 times in the value of scales. After further analysis, we figured out that the trial of Hua Fang ${ }^{13}$ contributed to the relatively high heterogeneity in $\mathrm{BI}$ score.And the heterogeneity would be reduced by $20 \%$ after dropping this trial. Usually, the major negative reaction 
of muscle discomfort was detected which was caused due to excessive muscle stimulation and improper adaptation to electrical stimulation. And this negative effect could be reduced by adjusting the NMES parameters and intensity ${ }^{41}$. However, during NMES therapy in these selected trials, no adverse effect was reported.

There are still some limitations in this analysis; the findings should be interpreted cautiously. First, we involved 3 trials $^{13-15}$, which were published in China not in SCI journals, low assessment may affect the overall results of the analysis, and the impact of NMES may have been assessed to be greater than actual, due to small bias. In addition, the relatively small sample size may give an uncorrected conclusion. Besides these selected RCTs, one trial ${ }^{14}$ used NMES as a the control group and contra laterally controlled functional electrical stimulation (CCFES) was considered as the experimental group. But in this study ,NMES group was selected as the intervention group. Finally, bias exists due to lack of blinded experimenters and participants. This is because it is difficult to get rid of observation bias during an intervention such as EMG-triggered NMES and so on.

\section{Conclusion}

To conclude, NMES has a positive influence on improving upper limb motor function, involving FMA-ue, ARAT and MAL-AOU in hemiplegic patients, specific to NMES therapy within 4 weeks. Our study may offer therapists a guide for future hemiparesis rehabilitation in patients after stroke. However, further studies including larger size and higher quality trials are needed to determine its true efficacy.

\section{Declarations}

\section{Ethics approval and consent to participate}

Not applicable.

\section{Competing interests}

Authors have no competing interests.

\section{Funding}

The article processing charge was funded by the Natural Science Foundation of China (grant no. 81171560), the "Par-Eu Scholars Program" of Chongqing City and the National Science and Technology Major Project of China (grant no. 2012ZX10002007001). The funding body had no role in design or interpretation of the study.

\section{Availability of data and materials}

The tables and figures supporting the conclusions of this article are included within the article.

\section{Authors' contributions}

WYZ and SYP contributed to the conception and design of the study. WYZ and YT conducted the literature search and data extraction, performed the statistical analyses. WYZ, YT and JH drafted the manuscript. HDH supervised the study. All authors have read and approved the manuscript.

\section{Acknowledgements}


Not applicable.

\section{Authors' information}

Wenyue Zhang E-mail: 785066793@qq.com

Shuye Pei E-mail:1084531419@qq.com

Yao Tang E-mail: selenre@qq.com

Juan Huang Email: 2420201272@qq.com

Huaidong Hu E-mail: huhuaidong@cqmu.edu.cn

\section{Abbreviations}

NMES=neuromuscular electrical stimulation

FES=functional electrical stimulation

TENS=transcutaneous electrical nerve stimulation

$\mathrm{EMG}=$ electromyography

FMA-ue= upper extremity component of the Fugl-Meyer motor assessment

MAS=modified ashworth scale

$\mathrm{Bl}=$ barthel index

ARAT=action research arm test

MAL-AOU= motor activity log and amount of use

$\mathrm{Cl}=$ confidence interval

\section{References}

1. Collaborators GCoD. Global, regional, and national age-sex specific mortality for 264 causes of death, 1980 2016: a systematic analysis for the Global Burden of Disease Study 2016. Lancet (London, England) 2017; 390: 1151-1210. 2017/09/19. DOI: 10.1016/s0140-6736(17)32152-9.

2. Collaborators GDaH. Global, regional, and national disability-adjusted life-years (DALYs) for 333 diseases and injuries and healthy life expectancy (HALE) for 195 countries and territories, 1990-2016: a systematic analysis for the Global Burden of Disease Study 2016. Lancet (London, England) 2017; 390: 1260-1344. 2017/09/19. DOI: 10.1016/s0140-6736(17)32130-x.

3. Feigin VL, Krishnamurthi RV, Parmar P, et al. Update on the Global Burden of Ischemic and Hemorrhagic Stroke in 1990-2013: The GBD 2013 Study. Neuroepidemiology 2015; 45: 161-176. 2015/10/28. DOI:

$10.1159 / 000441085$. 
4. Feigin VL. Stroke epidemiology in the developing world. Lancet (London, England) 2005; 365: 2160-2161. 2005/06/28. DOI: 10.1016/s0140-6736(05)66755-4.

5. RY W, YR Y, MW T, et al. Effects of functional electric stimulation on upper limb motor function and shoulder range of motion in hemiplegic patients. American journal of physical medicine \& rehabilitation 2002.

6. Malouin F, Pichard L, Bonneau C, et al. Evaluating motor recovery early after stroke: comparison of the FuglMeyer Assessment and the Motor Assessment Scale. Archives of physical medicine and rehabilitation 1994; 75: 1206-1212. 1994/11/01.

7. Buma F, Kwakkel G and Ramsey N. Understanding upper limb recovery after stroke. Restorative neurology and neuroscience 2013; 31: 707-722. 2013/08/22. DOI: 10.3233/rnn-130332.

8. Knutson JS, Fu MJ, Sheffler LR, et al. Neuromuscular Electrical Stimulation for Motor Restoration in Hemiplegia. Physical medicine and rehabilitation clinics of North America 2015; 26: 729-745. 2015/11/03. DOI: 10.1016/j.pmr.2015.06.002.

9. Dirks ML, Wall BT, Snijders T, et al. Neuromuscular electrical stimulation prevents muscle disuse atrophy during leg immobilization in humans. Acta physiologica (Oxford, England) 2014; 210: 628-641. 2013/11/21. DOI: 10.1111/apha.12200.

10. Takeda K, Tanino $\mathrm{G}$ and Miyasaka $\mathrm{H}$. Review of devices used in neuromuscular electrical stimulation for stroke rehabilitation. Medical devices (Auckland, NZ) 2017; 10: 207-213. 2017/09/09. DOI: 10.2147/mder.S123464.

11. Dehail P, Duclos $C$ and Barat M. Electrical stimulation and muscle strengthening. Annales de readaptation et de medecine physique : revue scientifique de la Societe francaise de reeducation fonctionnelle de readaptation et de medecine physique 2008; 51: 441-451. 2008/07/08. DOI: 10.1016/j.annrmp.2008.05.001.

12. Maffiuletti NA. Physiological and methodological considerations for the use of neuromuscular electrical stimulation. European journal of applied physiology 2010; 110: 223-234. 2010/05/18. DOI: 10.1007/s00421010-1502-y.

13. Hua F, Zhixian Z and Guifen L. Effect of functional electrical stimulation intervention therapy on rehabilitation of motor dysfunction after stroke Chines Journal of Clinical Rehabilitation 2004.

14. Ying S, Zhifei Y and Wenjun D. Effects of contralaterally controlled functional electrical stimulation on upper limb functions in patients with stroke. Chinese Journal of Rehabilitation Medicine 2014; 29(12). DOI: 10.3969/j.issn.1001-1242.2014.12.004.

15. Chunzhen L, Youxiang S, Wanzhang Y, et al. Effects of motor imaginary therapy combined with neuromuscular electrical stimulation on the functional outcomes of upper limb in patients with hemiplegia of convalescence cerebral infarction. Chinese Journal of Rehabilitation Medicine 2009.

16. Higgins JP, Altman DG, Gotzsche PC, et al. The Cochrane Collaboration's tool for assessing risk of bias in randomised trials. BMJ (Clinical research ed) 2011; 343: d5928. 2011/10/20. DOI: 10.1136/bmj.d5928.

17. Qian Q, Hu X, Lai Q, et al. Early Stroke Rehabilitation of the Upper Limb Assisted with an ElectromyographyDriven Neuromuscular Electrical Stimulation-Robotic Arm. Frontiers in neurology 2017; 8: 447. 2017/09/21. DOI: 10.3389/fneur.2017.00447.

18. Wilson RD, Page SJ, Delahanty M, et al. Upper-Limb Recovery After Stroke: A Randomized Controlled Trial Comparing EMG-Triggered, Cyclic, and Sensory Electrical Stimulation. Neurorehabilitation and neural repair 2016; 30: 978-987. 2016/05/27. DOI: 10.1177/1545968316650278.

19. Higgins JPT and (editors) GS. Cochrane Handbook for Systematic Reviews of Interventions Version 5.1.0. The Cochrane Collaboration 2011. 
20. Hsu SS, Hu MH, Luh JJ, et al. Dosage of neuromuscular electrical stimulation: is it a determinant of upper limb functional improvement in stroke patients? Journal of rehabilitation medicine 2012; 44: 125-130. 2012/01/24. DOI: 10.2340/16501977-0917.

21. Noma T, Matsumoto S, Shimodozono M, et al. Novel neuromuscular electrical stimulation system for the upper limbs in chronic stroke patients: a feasibility study. American journal of physical medicine \& rehabilitation 2014; 93: 503-510. 2014/02/11. DOI: 10.1097/phm.0000000000000056.

22. Powell J, Pandyan AD, Granat M, et al. Electrical stimulation of wrist extensors in poststroke hemiplegia. Stroke 1999; 30: 1384-1389. 1999/07/02.

23. Francisco G, Chae J, Chawla H, et al. Electromyogram-triggered neuromuscular stimulation for improving the arm function of acute stroke survivors: a randomized pilot study. Archives of physical medicine and rehabilitation 1998; 79: 570-575. 1998/05/22.

24. Nakipoglu Yuzer GF, Kose Donmez B and Ozgirgin N. A Randomized Controlled Study: Effectiveness of Functional Electrical Stimulation on Wrist and Finger Flexor Spasticity in Hemiplegia. Journal of stroke and cerebrovascular diseases : the official journal of National Stroke Association 2017; 26: 1467-1471. 2017/05/04. DOI: 10.1016/j.jstrokecerebrovasdis.2017.03.011.

25. Moher D, Liberati A, Tetzlaff J, et al. Preferred reporting items for systematic reviews and meta-analyses: the PRISMA statement. PLoS medicine 2009; 6: e1000097. 2009/07/22. DOI: 10.1371/journal.pmed.1000097.

26. Hsu SS, Hu MH, Wang YH, et al. Dose-response relation between neuromuscular electrical stimulation and upper-extremity function in patients with stroke. Stroke 2010; 41: 821-824. 2010/03/06. DOI: 10.1161/strokeaha.109.574160.

27. Kojima K, Ikuno K, Morii Y, et al. Feasibility study of a combined treatment of electromyography-triggered neuromuscular stimulation and mirror therapy in stroke patients: a randomized crossover trial.

NeuroRehabilitation 2014; 34: 235-244. 2014/01/15. DOI: 10.3233/nre-131038.

28. Shimodozono M, Noma T, Matsumoto $S$, et al. Repetitive facilitative exercise under continuous electrical stimulation for severe arm impairment after sub-acute stroke: a randomized controlled pilot study. Brain injury 2014; 28: 203-210. 2013/12/07. DOI: 10.3109/02699052.2013.860472.

29. McCabe J, Monkiewicz M, Holcomb J, et al. Comparison of robotics, functional electrical stimulation, and motor learning methods for treatment of persistent upper extremity dysfunction after stroke: a randomized controlled trial. Archives of physical medicine and rehabilitation 2015; 96: 981-990. DOI: 10.1016/j.apmr.2014.10.022.

30. Chae J, Bethoux F, Bohine T, et al. Neuromuscular stimulation for upper extremity motor and functional recovery in acute hemiplegia. Stroke 1998; 29: 975-979. 1998/05/22.

31. Carda S, Biasiucci A, Maesani A, et al. Electrically Assisted Movement Therapy in Chronic Stroke Patients With Severe Upper Limb Paresis: A Pilot, Single-Blind, Randomized Crossover Study. Archives of physical medicine and rehabilitation 2017; 98: 1628-1635.e1622. 2017/05/14. DOI: 10.1016/j.apmr.2017.02.020.

32. Boyaci A, Topuz O, Alkan H, et al. Comparison of the effectiveness of active and passive neuromuscular electrical stimulation of hemiplegic upper extremities: a randomized, controlled trial. International journal of rehabilitation research Internationale Zeitschrift fur Rehabilitationsforschung Revue internationale de recherches de readaptation 2013; 36: 315-322. 2013/04/13. DOI: 10.1097/MRR.0b013e328360e541.

33. Hochsprung A, Dominguez-Matito A, Lopez-Hervas A, et al. Short- and medium-term effect of kinesio taping or electrical stimulation in hemiplegic shoulder pain prevention: A randomized controlled pilot trial. 
NeuroRehabilitation 2017; 41: 801-810. 2017/12/20. DOI: 10.3233/nre-172190.

34. Kowalczewski J, Gritsenko V, Ashworth N, et al. Upper-extremity functional electric stimulation-assisted exercises on a workstation in the subacute phase of stroke recovery. Archives of physical medicine and rehabilitation 2007; 88: 833-839. 2007/07/03. DOI: 10.1016/j.apmr.2007.03.036.

35. Rosewilliam S, Malhotra S, Roffe C, et al. Can surface neuromuscular electrical stimulation of the wrist and hand combined with routine therapy facilitate recovery of arm function in patients with stroke? Archives of physical medicine and rehabilitation 2012; 93: 1715-1721.e1711. 2012/06/09. DOI:

10.1016/j.apmr.2012.05.017.

36. de Kroon JR and MJ IJ. Electrical stimulation of the upper extremity in stroke: cyclic versus EMG-triggered stimulation. Clinical rehabilitation 2008; 22: 690-697. 2008/08/06. DOI: 10.1177/0269215508088984.

37. Monte-Silva K, Piscitelli D, Norouzi-Gheidari N, et al. Electromyogram-Related Neuromuscular Electrical Stimulation for Restoring Wrist and Hand Movement in Poststroke Hemiplegia: A Systematic Review and MetaAnalysis. Neurorehabilitation and neural repair 2019; 33: 96-111. 2019/02/02. DOI: $10.1177 / 1545968319826053$.

38. Kwakkel G, Kollen B and Lindeman E. Understanding the pattern of functional recovery after stroke: facts and theories. Restorative neurology and neuroscience 2004; 22: 281-299. 2004/10/27.

39. Dobkin $\mathrm{BH}$. Rehabilitation and functional neuroimaging dose-response trajectories for clinical trials. Neurorehabilitation and neural repair 2005; 19: 276-282. 2005/11/03. DOI: 10.1177/1545968305281892.

40. Wissel J, Manack A and Brainin M. Toward an epidemiology of poststroke spasticity. Neurology 2013; 80: S1319. 2013/01/18. DOI: 10.1212/WNL.0b013e3182762448.

41. Maffiuletti NA, Vivodtzev I, Minetto MA, et al. A new paradigm of neuromuscular electrical stimulation for the quadriceps femoris muscle. European journal of applied physiology 2014; 114: 1197-1205. 2014/02/26. DOI: 10.1007/s00421-014-2849-2.

\section{Table}

Table 1 Concluding of basic characteristics of included studies 


\begin{tabular}{|c|c|c|c|c|c|c|}
\hline \multirow[t]{2}{*}{ AuthorロYear } & \multicolumn{2}{|c|}{ ParticipantComplete } & \multirow{2}{*}{$\begin{array}{l}\text { Intervention } \\
\text { Type }\end{array}$} & \multirow{2}{*}{$\begin{array}{l}\text { Age Post } \\
\text { stroke } \\
\text { duration }\end{array}$} & \multicolumn{2}{|c|}{ Intervention main outcomes } \\
\hline & number & number(male\%) & & & times & measure \\
\hline $\begin{array}{l}\text { boyaci } \\
\mathrm{A}, 2013\end{array}$ & 31 & $31(58.1 \%)$ & $\begin{array}{l}\text { active } \\
\text { NMES, } \\
\text { passive }\end{array}$ & $\begin{array}{l}59.4 \square 4 \\
\text { weeks }\end{array}$ & 3 weeks & $\begin{array}{l}\text { FMA-ue,MAL-AOU } \\
\text { /QOM, FIM,Wrist } \\
\text { MAS }\end{array}$ \\
\hline Carda S,2017 & 11 & $11(63.6 \%)$ & EAMT-SC & $\begin{array}{l}47.9 \square 6 \\
\text { months }\end{array}$ & 5 weeks & $\begin{array}{l}\text { FMA-ued } \\
\text { WMF, MAL- }\end{array}$ \\
\hline Chae J,1998 & 46 & $28(46.4 \%)$ & NMES & $59.7 \square 4$ & 2 weeks & FMA-ue, self-care \\
\hline de Kroon & 22 & $21(76.2 \%)$ & cyclic NMES & $59 \quad$ weeks & 6 weeks & ARAT,FMA, MI \\
\hline Hochsprung & 31 & $21(61.9 \%)$ & NMES & $62.5 \square 6$ & 24 weeks & BI,ARAT,BS \\
\hline Hsu ss, 2010 & 66 & $66(63.6 \%)$ & $\begin{array}{l}\text { high NMES, } \\
\text { low NMES }\end{array}$ & $\begin{array}{c}62.6 \square 3 \\
\text { months }\end{array}$ & 4 weeks & $\begin{array}{l}\text { ARAT,MAL- } \\
\text { AOU,MAL- }\end{array}$ \\
\hline Hua & 86 & $86(65.1 \%)$ & FES & $65 \quad \ldots$ & $\ldots$ & FMA-ue,MBI \\
\hline $\begin{array}{l}\text { Jessica } \\
\text { M.2015 }\end{array}$ & 39 & $35(65.7 \%)$ & $\mathrm{ML}+\mathrm{FES}$ & ... $\quad$ प1 year & 12 weeks & AMAT,FMA-ue \\
\hline Kowalczewski & 20 & $19 \square 52.6 \% \square$ & high- & $60.6 \square 3$ & 4 weeks & FM \\
\hline $\begin{array}{l}\text { Kojima } \\
\text { K,2014 }\end{array}$ & 13 & $13(76.9 \%)$ & $\begin{array}{l}\text { immediate } \\
\text { ETMS-MT }\end{array}$ & $\begin{array}{c}69.2 \square 6 \\
\text { months }\end{array}$ & 4 weeks & $\begin{array}{l}\text { FMA- } \\
\text { ue,WMFT,MAL- }\end{array}$ \\
\hline Li,2009 & 60 & $60(55 \%)$ & $\begin{array}{l}\text { motor } \\
\text { imaginary }\end{array}$ & $\begin{array}{l}56.9 \llbracket 3 \\
\text { months }\end{array}$ & $\ldots$. & $\begin{array}{l}\text { FMA-ue } \\
\text {,STEF,MBI }\end{array}$ \\
\hline Q Qian,2017 & 24 & $24(62.5 \%)$ & NMES-robot & $59.6 \square 4$ & 4 weeks & FMA- \\
\hline $\begin{array}{l}\text { Rosewilliam } \\
\text { S,2012 }\end{array}$ & 90 & $67(46.3 \%)$ & surface & $74 \quad \square 6$ & 6 weeks & ARAT,BI,Wrist \\
\hline $\begin{array}{l}\text { Shimodozono } \\
\text { M,2014 }\end{array}$ & 27 & $27(74.1 \%)$ & $\mathrm{REF}+\mathrm{NME}$ & $61.5 \square 13$ & 4 weeks & FMA,MAS \\
\hline $\begin{array}{l}\text { Shen } \\
\text { Ying,2014 }\end{array}$ & 60 & $60 \square 73.3 \% \square$ & NMES & 60.303 & 3 weeks & FMA-UE,MI, \\
\hline $\begin{array}{l}\text { Wilson } \\
\text { RD,2016 }\end{array}$ & 122 & $122(58.1 \%)$ & $\begin{array}{l}\text { cyclic } \\
\text { NMES,EMG } \\
\text { Triggered } \\
\text { NMES }\end{array}$ & $\begin{array}{l}56.5 \square 6 \\
\text { months }\end{array}$ & 8 weeks & $\begin{array}{l}\text { FMA-ue[FMA- } \\
\text { wh,AMAT }\end{array}$ \\
\hline
\end{tabular}

EMG=electromyography, FES=functional electric stimulation, ET= exercise therapy, MT=Mirror therapy ,ETMS=electromyography-triggered neuromuscular stimulation, AMAT=Arm Motor Ability Test, WMF=Wolf Motor Function Test, EAMT=electrically assisted movement therapy ,SC= Standard care, $\mathrm{REF}=$ repetitive facilitative exercise, $\mathrm{MAL}=$ Motor Activity Log, AOU=amount of use, QOM=quality of movement, ue=upper limb, wh=Wrist and Hand, FMA=Fugl-Meyer Motor Assessment, BI=Barthel Index, ARAT=Action Research Arm Test, BS=berg scale, MI=Motricity Index, FIM=Functional Independence Measure, MAS=modify ashworth scale, STEF=Simple test for evaluating hand function.

\section{Figures}




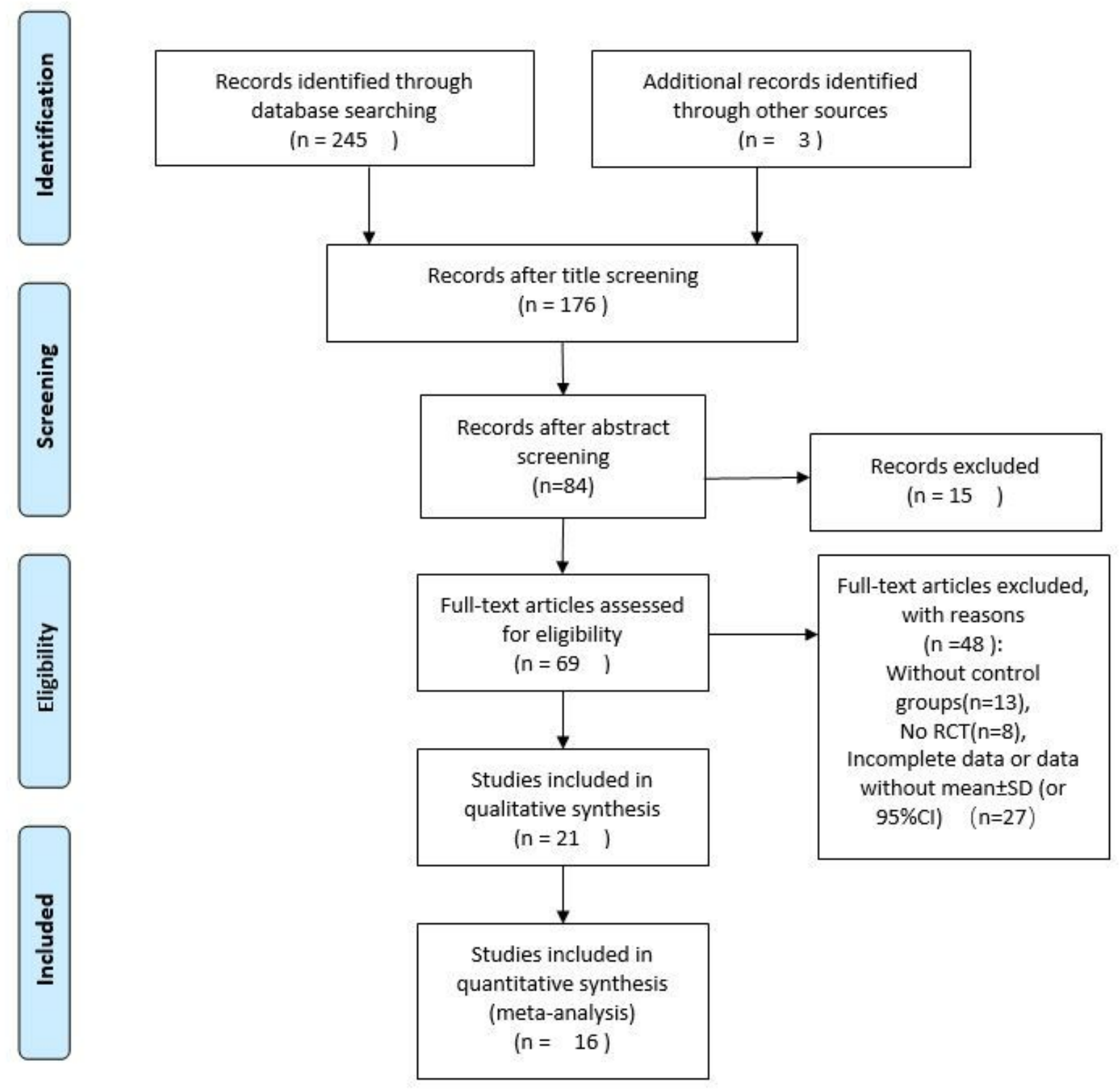

Figure 1

PRISMA Diagram

\section{Figure 2}

Figure2A Forest plot of the meta-analysis for comparing experimental with control groups in FMA-ue. Figure2B Forest plot of the meta-analysis for comparing experimental with control groups in wrist MAS. Figure2C Forest plot of the meta-analysis for comparing experimental with control groups in ARAT. Figure2D Forest plot of the metaanalysis for comparing experimental with control groups in MAL-AOU. Figure2E Forest plot of the meta-analysis for comparing experimental with control groups in $\mathrm{BI}$. 


\section{Figure 3}

Begg 's and Egger's tests

\section{Supplementary Files}

This is a list of supplementary files associated with this preprint. Click to download.

- sub.tif

- PRISMA2009ChecklistMSWord1.doc

- riskofbias.doc 